\title{
Ten key considerations for the successful implementation and adoption of large-scale health information technology
}

\author{
Kathrin M Cresswell, ${ }^{1}$ David W Bates, ${ }^{2,3}$ Aziz Sheikh ${ }^{4}$
}

\begin{abstract}
The School of Health in Socia Science, The University of Edinburgh, Edinburgh, UK ${ }^{2}$ Department of Medicine, Brigham and Women's Hospital, Harvard Medical School, Boston, Massachusetts, USA

${ }^{3}$ The Department of Health Policy and Management, Harvard School of Public Health, Boston, Massachusetts, USA

${ }^{4}$ eHealth Research Group, Centre for Population Health Sciences, The University of Edinburgh, Edinburgh, UK
\end{abstract}

\section{Correspondence to} $\mathrm{K}$ Cresswell, The School of Health in Social Science, The University of Edinburgh, Edinburgh EH8 9DX, UK: kathrin.beyer@ed.ac.uk

Received 30 January 2013 Revised 4 March 2013 Accepted 1 April 2013 Published Online First 18 April 2013

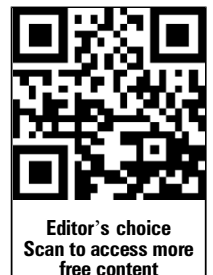

To cite: Cresswell KM Bates DW, Sheikh A. J Am Med Inform Assoc 2013:20: e9-e13.

\section{ABSTRACT}

The implementation of health information technology interventions is at the forefront of most policy agendas internationally. However, such undertakings are often far from straightforward as they require complex strategic planning accompanying the systemic organizational changes associated with such programs. Building on our experiences of designing and evaluating the implementation of large-scale health information technology interventions in the USA and the UK, we highlight key lessons learned in the hope of informing the on-going international efforts of policymakers, health directorates, healthcare management, and senior clinicians.

\section{INTRODUCTION}

Large-scale, potentially transformative, implementations of health information technology are now being planned and undertaken in multiple countries. ${ }^{1}$ The hope is that the very substantial financial, human, and organizational investments being made in electronic health records, electronic prescribing, whole-system telehealthcare, and related technologies will streamline individual and organizational work processes and thereby improve the quality, safety, and efficiency of care. The reality is, however, that these technologies may prove frustrating for frontline clinicians and organizations as the systems may not fit their usual workflows, and the anticipated individual and organizational benefits take time to materialize. ${ }^{3}{ }^{4}$ In this article, we reflect on our mapping of the literature (see box 1) and complement this with our experiences of studying a range of national evaluations of various large-scale health information technology systems in the UK and USA to provide key pointers that can help streamline implementation efforts. ${ }^{4}{ }^{52-54}$ In so doing, we hope to inform policy and practice development to support the more successful integration of technology into complex healthcare environments. This is particularly timely given the US Health Information Technology for Economic and Clinical Health (HITECH) Act, which includes a $\$ 19$ billion stimulus package to promote the adoption of electronic health records and associated functionality. ${ }^{55}$

This paper complements a previous publication by Bates and colleagues on 'Ten commandments for effective clinical decision support', ${ }^{11}$ which focused on lessons learned in relation to clinical decision support systems. We have developed a technology lifecycle approach to highlight key considerations at four stages: establishing the need for change, selecting a system, implementation planning, and maintenance and evaluation (figure 1).

\section{TEN KEY CONSIDERATIONS FOR THE SUCCESSFUL IMPLEMENTATION OF HEALTH INFORMATION TECHNOLOGY}

1. Clarify what problem(s) the technology is designed to help tackle

Many health information technology procurements are based on assumed benefits, which are often poorly specified. This can result in difficulties agreeing on a shared vision across the healthcare organization. While terms like 'improved quality of care' and 'improved efficiency' are often used, detailed outcomes resulting from specific functionality are hard to measure and to anticipate as most implementations require fundamental changes to operational processes and many organizations do not even attempt this. ${ }^{3} 452-54$ Thus, organizations often encounter difficulties conceptualizing the required short-, medium-, and long-term transformations.

A thorough mapping of existing local processes before implementation can mitigate this risk and help to identify existing problems as well as areas for improvement. In an ideal scenario, this groundwork would result in agreement on the problem(s) to be addressed by a specific functionality (eg, duplication of information) and, based on this, the development of a long-term strategic vision (eg, a common patient record that is populated by all health professionals). However, new technology may not always be the answer. It is therefore also important to assess if, and to what extent, existing/ new health information technology can support these strategic goals and whether other approaches may also need to be considered.

\section{Build consensus}

Professional, managerial, and administrative consensus needs to be built around the strategic vision, in addition to creating the means to support the realization of this vision. ${ }^{56}$ This may involve considering whether to aim for radical changes across the organization (eg, through implementing electronic health record functionality), or whether to focus on streamlining specific processes (eg, electronic prescribing) initially and then expanding functionality over time. Many authors in the field of organizational change have highlighted that high-level strategic leadership of senior management including both administrative and clinical leaders is vital, and this is accurate, but it is also essential to involve and get the buy-in of different professional stakeholder groups (eg, doctors, 
Box 1 Factors associated with effective implementation identified in the literature ${ }^{5-51}$

Technical: usability, system performance, integration and interoperability, stability and reliability, adaptability and flexibility, cost, accessibility and adaptability of hardware

Social: attitudes and concerns, resistance and workarounds, expectations, benefits/values and motivations, engagement and user input in design, training and support, champions, integration with existing work practices

Organizational: getting the organization ready for change, planning, leadership and management, realistic expectations, user ownership, teamwork and communication, learning and evaluation

Wider socio-political: other healthcare organizations, industry, policy, professional groups, independent bodies, the wider economic environment, international developments

nurses, administrative staff, managers) in order to facilitate co-ownership and ensure commitment. ${ }^{57}$ From our experience, this balance is best achieved through the creation of a high-level strategic group that not only includes senior managers, but also clinical and administrative leads who represent different end-user groups.

An important factor to keep in mind is that attempts to align perspectives through, for example, consensus building activities, need to be skillfully handled with cognizance of the means to overcome rather than perpetuate existing professional hierarchies. One approach that we have successfully used is to identify domains in which there is already broad agreement versus those which need specific attention from different professional stakeholders. For the latter, efforts promoting the participation and empowerment of different groups by actively searching for inclusive solutions, have the highest potential to achieve coordinated implementation efforts. ${ }^{59}$ Nurses, for instance, will have different needs to doctors, but all groups tend to agree that the provision of high standards of care should be the focus of activities. Patient-centered discussions could therefore be a point of convergence between different professional viewpoints.

\section{Consider your options}

Once the need for a technological system has been established, it is important to commit adequate time and resources to thoroughly consider different options in terms of which system(s) to choose. We have found that this aspect of planning and the associated writing of business cases and procurement considerations are sometimes under-estimated and often rushed. ${ }^{11} 52$ It is, for example, important to be aware of the full range of system providers, and network with potential suppliers in order to understand the ethos and values of the companies with which the organization is considering embarking on a long-term relationship. Visiting other healthcare settings that have implemented similar technology can prove very helpful. ${ }^{52}$

Once available commercial systems have been appraised, it is appropriate to reflect on whether to build a customized system tailored to local needs, whether to customize an existing system, or whether to use an 'off-the-shelf' standardized solution. ${ }^{58}$ The literature and our experiences indicate that there are inherent risks and benefits to each of these approaches. For example, although 'home-grown' customized systems tend to be better accepted by local users than standardized solutions, they are also not a cheap option and often do not easily integrate with
Figure 1 Summary of the lifecycle stages of health information technology and the ten key considerations.
Ten key considerations

\begin{tabular}{|c|}
\hline $\begin{array}{l}\text { 1. Clarify what problem(s) the technology is } \\
\text { designed to help tackle }\end{array}$ \\
\hline 2. Build consensus \\
\hline 3. Consider your options \\
\hline $\begin{array}{l}\text { 4. Choose systems that meet clinical needs and are } \\
\text { affordable }\end{array}$ \\
\hline 5. Plan appropriately \\
\hline 6. Don't forget the infrastructure \\
\hline 7. Have a plan to train staff \\
\hline 8. Continuously evaluate progress \\
\hline 9. Maintain the system \\
\hline 10. Stay the course \\
\hline
\end{tabular}

Technology lifecycle stages
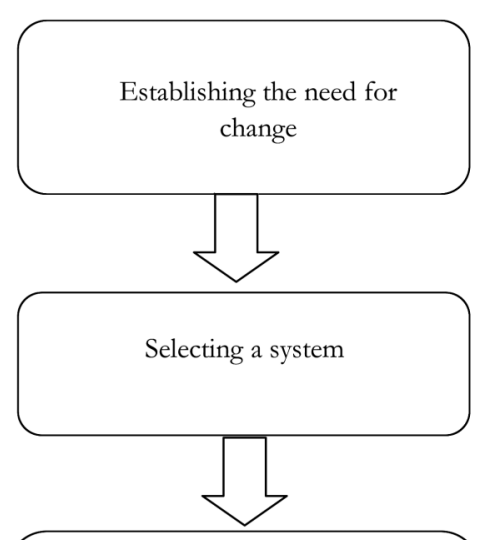

Planning (implementation strategy, infrastructure, training)

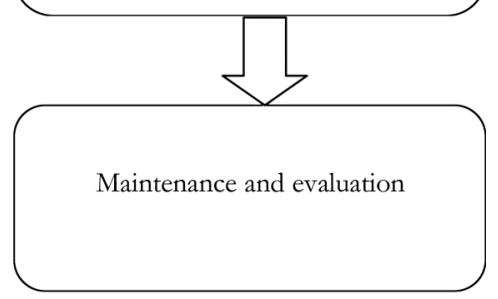


other technological systems in the organization. ${ }^{4}{ }^{52-54}$ In addition, considerable time is needed to customize systems, and such efforts are often led by individuals or small groups of enthusiasts and so may not have longevity. In the USA, for example, commercial systems have markedly improved in recent years and now dominate the marketplace. Internationally, most organizations will, we anticipate, also choose commercial systems in the future due to cost and interoperability considerations. Commercial systems are cheaper to purchase (as they are not customized to individual organizations and can therefore be produced in bulk) and they are also likely to be interoperable due to common data standards and architectures (such as, for example, the Health Level Seven International interoperability standards).

\section{Choose systems that meet clinical needs and are affordable}

Once a decision on the basic type of system has been made, it is important to base the final choice not only on organizational, but also on clinical needs. ${ }^{60} \mathrm{~A}$ system should be both fit for organizational purpose and fit for clinical practice. There are countless examples of systems that have been procured but never used (eg, if they are perceived to undermine professional values) or are deployed in unintended ways, which will then typically result in a failure to realize the hoped for improvements (see box 2, example 1). ${ }^{4} 61$

A system therefore needs to fulfill a range of requirements on a variety of levels. It needs to be usable for end-users (not cumbersome for clinicians and beneficial for patients), cost-effective for organizations, and interoperable to allow secondary uses of data. These purposes are often difficult to align as requirements of different domains may result in trade-offs for others. ${ }^{60}$ For example, it has repeatedly been found that many health information technologies slow down the work practices of users, despite improving overall organizational efficiency. ${ }^{62}$ Speed is of the essence and any initiative that slows down key clinical tasks is likely to be strongly resisted by frontline staff. This issue can to some extent be addressed by purchasing systems that allow a large degree of customization, but these are often expensive to acquire and run, necessitating a careful balancing act between affordability and desired functionality. Our experiences suggest that the associated system costs are often under-estimated, particularly those relating to infrastructure, support, and maintenance.

\section{Plan appropriately}

It takes both targeted and reflective efforts to plan for transformative organizational ventures of any kind. Although flexibility in strategy is required, there are some general pointers that tend to characterize effective preparation across organizations and technologies. These include the aforementioned necessity to engage extensively with potential suppliers and other organizations who have already implemented, but also the decision to prioritize the implementation of functionality that can bring benefits to the greatest number of end-users as early as possible. ${ }^{4} 52-54$ Other factors relate to the avoidance of 'scopecreep' (ie, the tendency to increase the scope of a project when it is already underway) and maintaining open channels of communication between management and users.

Implementation strategies need to be tailored to organizational circumstances and systems, whether they involve 'phased' or 'big-bang' implementation approaches. The former relates to introducing incremental functionality slowly, while the latter relates to introducing functionality across the organization all at once. We suggest avoiding the running of parallel systems (both

\section{Box 2 Examples of 'failures' in implementation}

Example 1: Rejection by users ${ }^{61}$

May and colleagues evaluated the implementation of a videophone, which was intended to be used by primary care physicians to refer patients to a community mental health facility. The team conducted qualitative interviews and observations with clinicians, managerial staff, and patients in order to explore the acceptability of the technology. They found that some professional groups, including community psychiatric nurses and occupational therapists, resisted using the system as they felt that it impacted adversely on the therapeutic relationship with their patients.

Example 2: Bandwidth undermining system performance (authors' own experience)

At one large hospital, operational management was told by the information technology leadership that the hospital's network was at maximal bandwidth at budget time. The management decided that the hospital would wait a year to upgrade the network, and instead purchased an expensive new imaging technology. However, several months later the institution's systems began to 'brown out,' and it was taking up to 30 minutes for a single screen change. Although the leadership immediately reversed field and authorized a network upgrade, this took several months to implement and care delivery was substantially impaired in the interim.

Example 3: The importance of user feedback (authors' own experience)

Getting an 'early fix' on how long a new system is taking to use is especially critical. At one hospital which was a pioneer in order entry, a system was implemented and users were told they had to use it. However, the leadership had no clear idea how long it was actually taking front-line clinical users to do their work-something that took an hour before implementation was now taking several hours, which resulted in an unworkable situation for front-line users. This eventually resulted in a computer monitor being thrown through a hospital window, and a work action by the clinical users. That got the leadership's attention and major changes were made.

Example 4: Tracking system performance (authors' own experience)

Maintenance includes tracking how the system is performing, and how the decision support within it is performing. Such tracking is much easier if it is built in from the beginning. At one large hospital, the allergy over-ride rates were initially very low. However, a series of apparently innocuous changes in the decision support system were made by the responsible committee with the result that several years later, large numbers of alerts were being delivered, with nearly all being over-ridden. After these data were reviewed, the system could be tuned, and the unimportant alerts were turned off.

paper and electronic) wherever possible, as this tends to increase workloads for end-users and may inadvertently introduce new threats to patient safety. ${ }^{45-54}$

\section{Don't forget the infrastructure}

Developing the right infrastructure is an essential part of planning activity. If this is not afforded sufficient attention, then software systems may perform sub-optimally (eg, if wireless networks are unavailable or bandwidth is too narrow), or may be 
inaccessible to users altogether (eg, if there is a lack of available hardware). Again, this increases the possibility that systems are not used at all or used in ways other than intended, potentially compromising benefits and increasing risks associated with technological systems. ${ }^{4}$ We have repeatedly found that inappropriate infrastructure can negatively shape user attitudes towards software systems themselves, as it can impact on usability and performance. Inappropriate infrastructure, such as a slow wireless connection, may for example, reduce the speed of a system, which is an important (if not the most important) factor in determining adoption (box 2, example 2). ${ }^{11}$

\section{Train staff}

Trained users tend to be more satisfied with new technologies than those who have not been adequately trained. ${ }^{63}$ This may be due to a lack of understanding of system capabilities, which can in turn lead to workarounds whereby the new systems are used in unintended ways-or worse still—avoided completely.

The most effective training is that which is tailored to the individual roles of users, without being too restrictive as this can undermine understanding of how the whole system functions. Training needs to allow users to practice 'hands-on' and as closely simulate the actual working environment as possible. ${ }^{58} 64$ It is also ideally conducted shortly before the implementation as otherwise staff may forget important functions. There may be a need for compulsory (eg, in relation to approaches to maintaining patient confidentiality) as well as voluntary components, and some individuals may need more training than others. For instance, older users may never have used a computer and may therefore require more basic training than younger individuals, who tend to be more accustomed to computers. For infrequent users and in relation to systems that are subject to regular upgrades, continuous training may be necessary. From our experience, training should typically total about $40 \%$ of an implementation budget, but is the area most often left short.

\section{Continuously evaluate progress}

Although it is now widely recognized that evaluation is important when considering new technologies, the reality is that it is still, more often than not, an afterthought as immediate implementation activities take priority. ${ }^{65}$ Real-time, longitudinal data collection strategies providing formative feedback are desirable as emerging results can be incorporated in on-going implementation activity, but this is costly and time-consuming. However, it is essential to capture user feedback about problems that are identified and respond to it in a timely manner (box 2, example $3)$. In our experience, investments in evaluation activities are always worth it. These should begin with assessing existing and anticipated organizational and individual workflows, monitoring desired and undesired consequences, and tracking new innovative ways of working. ${ }^{42-54}$ It is also crucially important that this work is carried out over an appropriate length of time, as it may well take years for benefits and consequences to emerge. ${ }^{60}$ Following developments over the long term can further help identify when systems have become obsolete and when there is a need for new solutions.

\section{Maintain the system}

Maintenance is in many ways related to all of the above points as these issues need to be re-visited periodically throughout the technology lifecycle (see figure 1). Nevertheless, maintenance deserves particular attention as it is often under-estimated in relation to associated activities and cost. ${ }^{66}$ This is not only the case in relation to on-going costs (eg, pertaining to support, infrastructure, and system upgrades), but also costs relating to potential system changes as the strategic aims of organizations and therefore the capabilities of existing technological systems are likely to change over time (box 2, example 4).

\section{Stay the course}

The benefits of major transformative ventures are notoriously difficult to measure and may take a long time to materialize. ${ }^{3} 452-54$ However, this is not to say that they are non-existent, rather they need to be tracked by appropriate evaluation work assessing how the new system is used and re-invented locally. This also requires an appreciation of the timelines surrounding the realization of expected benefits, allowing enough time for technologies to embed and data to be exploited for secondary uses. ${ }^{60}$ Our work has shown that in many cases the expectations of organizations and individual users far exceed what is achievable in the short term. The managing of expectations is, therefore, important as otherwise there is a danger that stakeholders disengage with the initiative and negative attitudes may emerge. ${ }^{452-54}$

\section{CONCLUSIONS}

Careful planning and on-going, critical evaluation of progress are central to the successful implementation of major health information technology. Taking a lifecycle perspective on the implementation of technological systems will, we hope, help organizations to avoid some of the all too commonly encountered pitfalls and improve the likelihood of successful implementation and adoption (see figure 1). It is, however, important to keep in mind that, although the stages and considerations discussed here were depicted in a linear manner, they may to some extent overlap. This is consistent with the complex nature of large-scale health information technology implementations, where a range of different inter-related factors are at play.

Acknowledgements We are very grateful to all participants who kindly gave their time and to the extended project and program teams of work we have drawn upon We are also grateful to two anonymous expert peer reviewers who commented on a previous version of this manuscript.

Contributors AS conceived this work. AS is currently leading a National Institute for Health Research-funded national evaluation of electronic prescribing and medicines administration systems. KMC is employed as a researcher on this grant and led on the write-up and drafting of the initial version of the paper, with DWB and AS commenting on various drafts.

Funding This work has drawn on data funded by the NHS Connecting for Health Evaluation Programme (NHS CFHEP 001, NHS CFHEP 005, NHS CFHEP 009, NHS CFHEP 010) and the National Institute for Health Research (NIHR)-funded Programme Grants for Applied Research scheme (RP-PG-1209-10099). The views expressed are those of the author(s) and not necessarily those of the NHS, the NIHR, or the Department of Health.

\section{Competing interests None.}

Provenance and peer review Not commissioned; externally peer reviewed.

\section{REFERENCES}

1 Morrison Z, Robertson A, Cresswell K, et al. Understanding and contrasting approaches to nationwide implementations of electronic health record systems: England, the USA and Australia. J Healthc Eng 2011;2:25-42.

2 Bates $D$. Using information technology to reduce rates of medication errors in hospitals. BMJ 2000;320:788.

3 European Commission. Interoperable eHealth is Worth it. Securing benefits from Electronic Health Records and ePrescribing. Brussels: European Commission, 2010.

4 Sheikh A, Cornford T, Barber N, et al. Implementation and adoption of nationwide electronic health records in secondary care in England: final qualitative results from prospective national evaluation in "early adopter" hospitals. BMJ 2011;343:d6054.

5 Adler KG. How to successfully navigate your EHR implementation. Fam Pract Manag 2007;14:33-9.

6 Ammenwerth E, Iller C, Mahler C. IT-adoption and the interaction of task, technology and individuals: a fit framework and a case study. BMC Med Inform Decis Mak 2006:6:13. 
7 Ash J, Berg M. Report of conference Track 4: socio-technical issues of HIS. Int J Med Inform 2003;69:305-6.

8 Austin CJ, Hornberger KD, Shmerling JE. Managing information resources: a study of ten healthcare organizations. J Healthc Manag 2000;45:229-38.

9 Bali RK, Wickramasinghe N. Achieving successful EPR implementation with the penta-stage model. Int J Healthc Technol Manag 2008;9:97-105.

10 Bates DW, Ebell M, Gotlieb E, et al. A proposal for electronic medical records in U. S. primary care. J Am Med Inform Assoc 2003;10:1-10.

11 Bates DW, Kuperman GJ, Wang S, et al. Ten commandments for effective clinica decision support: making the practice of evidence-based medicine a reality. J Am Med Inform Assoc 2011;10:523-30.

12 Beuscart-Zephir MC, Anceaux F, Crinquette V, et al. Integrating users' activity modeling in the design and assessment of hospital electronic patient records: the example of anesthesia. Int J Med Inform 2001;64:157-71.

13 Boonstra A, Broekhuis M. Barriers to the acceptance of electronic medical records by physicians from systematic review to taxonomy and interventions. BMC Health Serv Res 2010;10:231

14 Bossen C. Test the artefact-develop the organization. The implementation of an electronic medication plan. Int J Med Inform 2007;76:13-21.

15 Callen JL, Braithwaite J, Westbrook JI. Contextual implementation model: a framework for assisting clinical information system implementations. J Am Med Inform Assoc 2008;15:255-62

16 Chaudhry B, Wang J, Wu S, et al. Systematic review: impact of health information technology on quality, efficiency, and costs of medical care. Ann Intern Med 2006;144:742-52

17 Clemmer TP. Computers in the ICU: where we started and where we are now. J Crit Care 2004:4:201-7.

18 Crosson JC, Stroebel C, Scott JG, et al. Implementing an electronic medical record in a family medicine practice: communication, decision making, and conflict. Ann Fam Med 2005;3:307-11.

19 Dagroso D, Williams PD, Chesney JD, et al. Implementation of an obstetrics EMR module: overcoming user dissatisfaction. J Healthc Inf Manag 2007:21:87-94.

20 Davidson $\mathrm{E}$, Chiasson M. Contextual influences on technology use mediation: a comparative analysis of electronic medical records systems. Eur J Info Syst 2005;14:6-18.

21 De Mul M, Berg M, Hazelzet JA. Clinical information systems: careSuite from Picis. J Crit Care 2004;19:208-14.

22 Duggan C. Implementation evaluation. HIM professionals share their experiences bringing health IT online. J AHIMA 2006;77:52-5.

23 Fenton SH, Giannangelo K, Stanfill M. Essential people skills for EHR implementation success. J AHIMA 2006:77:60.

24 Ferneley E, Sobreperez P. Resist, comply or workaround? An examination of different facets of user engagement with information systems. Eur J Inf Syst 2006;15:345-56.

25 Giuse DA, Kuhn KA. Health information systems challenges: the Heidelberg conference and the future. Int J Med Inform 2003;69:105-14.

26 Goroll AH, Simon SR, Tripathi M, et al. Community-wide implementation of health Information technology: the Massachusetts eHealth collaborative experience. J Am Med Inform Assoc 2009;16:132-9.

27 Granlien MF, Hertzum M, Gudmundsen J. The gap between actual and mandated use of an electronic medication record three years after deployment. Stud Health Technol Inform 2008;136:419-24.

28 Halamka J, Aranow M, Ascenzo C, et al. E-Prescribing collaboration in Massachusetts: early experiences from regional prescribing projects. J Am Med Inform Assoc 2006:13:239-44.

29 Hendy J, Reeves BC, Fulop N, et al. Challenges to implementing the national programme for information technology (NPfIT): a qualitative study. BMJ 2005;331:331-6.

30 James $D$, Hess S, Kretzing JE Jr, et al. Showing "what right looks like"-how to improve performance through a paradigm shift around implementation thinking. $J$ Healthc Inf Manag 2007;21:54-61.

31 Jones M. Learning the lessons of history? Electronic records in the United Kingdom acute hospitals, 1988-2002. Health Informatics J 2004;10:253-63.

32 Karsten $\mathrm{H}$, Laine $\mathrm{A}$. User interpretations of future information system use: a snapshot with technological frames. Int J Med Inform 2007;76:S136-40.

33 Keddie Z, Jones R. Information communications technology in general practice: cross-sectional survey in London. Inform Prim Care 2005;13:113-23.

34 Keshavjee K, Bosomworth J, Copen J, et al. Best practices in EMR implementation: a systematic review. AMIA Annu Symp Proc 2006;982.

35 Lium JT, Tjora A, Faxvaag A. No paper, but the same routines: a qualitative exploration of experiences in two Norwegian hospitals deprived of the paper based medical record. BMC Med Inform Decis Mak 2008;8.
36 Lorenzi NM, Smith JB, Conner SR, et al. The success factor profile for clinical computer innovation. Stud Health Technol Inform 2004;107:1077-80.

37 Lu Y-C, Xiao Y, Sears A, et al. A review and a framework of handheld computer adoption in healthcare. Int J Med Inform 2005;74:409-22.

38 Ludwick DA, Doucette J. Adopting electronic medical records in primary care: lessons learned from health information systems implementation experience in seven countries. Int J Med Inform 2009:78:22-31.

39 Mehta NB, Partin MH. Electronic health records: a primer for practicing physicians. Cleve Clin J Med 2007;74:826-30.

40 Miranda D, Fields W, Lund K. Lessons learned during 15 years of clinical information system experience. Comput Nurs 2001;4:147-51.

41 Moen A. A nursing perspective to design and implementation of electronic patient record systems. J Biomed Inform 2003;36:375-8.

42 Nikula RE. Why implementing EPR's does not bring about organizational changes-a qualitative approach. Stud Health Technol Inform 2001;84:666-9.

43 Ovretveit J, Scott T, Rundall TG, et al. Improving quality through effective implementation of information technology in healthcare. Int I Qual Health Care 2007;5:259-66.

44 Pagliari C. Implementing the national programme for IT: what can we learn from the Scottish experience? Inform Prim Care 2005;13:105-11.

45 Pare G. Implementing clinical information systems: a multiple-case study within a US hospital. Health Serv Manage Res 2002;15:71-92.

46 Pare $G$, Sicotte $C$, Jaana $M$, et al. Prioritizing the risk factors influencing the success of clinical information system projects. A Delphi study in Canada. Methods Inf Med 2008;47:251-9.

47 Pendergast DK, Buchda VL. Charting the course. A quality journey. Nurs Adm Q 2003:27:330-5.

48 Puffer MJ, Ferguson JA, Wright BC, et al. Partnering with clinical providers to enhance the efficiency of an EMR. J Healthc Inf Manag 2007;21:24-32.

49 Quinzio L, Junger A, Gottwald B, et al. User acceptance of an anaesthesia information management system. Eur J Anaesthesiol 2003;20:967-72.

50 Räisänen C, Linde A. Technologizing discourse to standardize projects in multi-project organizations: hegemony by consensus? Organization 2004;11:101-21

51 Rose J, Jones M, Truex D. Socio-theoretic accounts of IS: the problem of agency. Scand J Info Syst 2005:17:133-52.

52 Cresswell K, Coleman J, Slee A, et al. Investigating and learning lessons from early experiences of implementing ePrescribing systems into NHS hospitals: a questionnaire study. PLoS One 2013;8:e53369.

53 Ash JS, Stavri PZ, Kuperman GJ. A consensus statement on considerations for a successful CPOE implementation. J Am Med Inform Assoc 2003;10:229-34.

54 Health Information Technology Evaluation Toolkit. http://www.healthit.gov/ unintended-consequences/sites/default/files/pdf/Modulellpdf1.5.pdf (accessed 3 Jan 2013).

55 Blumenthal D. Stimulating the adoption of health information technology. New Engl J Med 2009:360:1477-9.

56 Markoczy L. Consensus formation during strategic change. Strategic Manage J 2001:22:1013-31.

57 Cresswell K, Morrison Z, Crowe S, et al. Anything but...engaged: user involvement in the context of a national electronic health record implementation. Inform Prim Care 2012:19:191-206.

58 Dagroso D, Williams PD, Chesney JD, et al. Implementation of an obstetrics EMR module: overcoming user dissatisfaction. J Healthc Inform Manage 2007;21:87-94.

59 Checkland P. Systems thinking, systems practice. Chichester: Wiley, 1981.

60 Cresswell K, Sheikh A. Effective integration of technology into health care needs adequate attention to sociotechnical processes, time and a dose of reality. JAMA 2012;307:2255

61 May C, Gask L, Atkinson T, et al. Resisting and promoting new technologies in clinical practice: the case of telepsychiatry. Soc Sci Med 2001;52:1889-901.

62 Aarts J, Doorewaard H, Berg M. Understanding implementation: the case of a computerized physician order entry system in a Large Dutch University Medical Center. J Am Med Inform Assoc 2004;11:207-16.

63 Yusof MM, Kuljis J, Papazafeiropoulou A, et al. An evaluation framework for Health Information Systems: human, organization and technology-fit factors (HOT-fit). Int J Med Inform 2008;77:386-98.

64 Sicotte C, Pare G, Moreault M-P, et al. A risk assessment of two interorganizational clinical information systems. J Am Med Inform Assoc 2006;13:557-66.

65 Greenhalgh T, Stramer K, Bratan T, et al. Introduction of shared electronic records: multi-site case study using diffusion of innovation theory. $B M J$ 2008;337:1786

66 McGowan JJ, Cusack CM, Poon EG. Formative evaluation: a critical component in EHR implementation. J Am Med Inform Assoc 2008;15:297-301. 